\title{
Tampilan Klinis pada Glaukoma Primer Sudut Terbuka di RSUP DR M Djamil Padang
}

\author{
Fitratul Ilahi, Vera
}

\begin{abstract}
Abstrak
Lebih dari 3 juta orang buta bilateral karena POAG di seluruh dunia, dan lebih dari 2 juta orang mengalami POAG setiap tahunnya. POAG yang tidak terdiagnosis merupakan reservoir terbesar dari kebutaan yang dapat dicegah dimana 30\% kasus belum terdiagnosis. Banyak pasien tidak terdeteksi dini dan datang dengan tampilan klinis yang lanjut, mengindikasikan perlunya program intervensi untuk deteksi dini dan perujukan kasus-kasus POAG untuk mencegah kehilangan fungsi penglihatan yang signifikan. Tujuan: Menjabarkan tampilan klinis POAG di RS DR. M. Djamil. Metode: Sejumlah 32 pasien POAG dari 229 pasien glaukoma didapat, dimana jumlah pasien laki-laki $(81,3 \%)$ lebih banyak dari pasien wanita $(18,7 \%)$. Umur pasien yang paling banyak ditemukan adalah di antara 51-70 tahun (62,6 \%). TIO dari 17,2, 3\% pasien adalah di atas $21 \mathrm{mmHg}$, dan 79,7\% di bawah $21 \mathrm{mmHg}$. Sebagian besar rasio cup/disc pasien adalah 0,9-1,0. Tampilan perimetri pasien menunjukkan defek altitudinal, defek arkuata, nasal step, temporal island, generalized depression, tunnel vision, dan skotoma perifer. Kesimpulan: Sebagian besar pasien POAG berumur 51-70 tahun, laki-laki, dan datang dengan tampilan klinis yang lanjut
\end{abstract}

Kata kunci: POAG, TIO, rasio cup/disc, perimetri.

\begin{abstract}
English, Arial 9 italic More than 3 million people are bilaterally blind from POAG worldwide, and more than 2 million people will develop POAG each year. Undiagnosed POAG is the greatest reservoir of preventable blindness were more than $50 \%$ of cases have been diagnosed yet. Many patients were not detected early and found in late clinical appearance, indicate the need for an intervention program for early detection and referral of POAG cases in order to prevent significant visual loss. Objective: The aim of our study is to describe clinical features of POAG in Dr.M.Djamil hospital as tertiary referral hospital.Methods: This retrospective study was conducted at ophthalmology department M. Djamil Hospital Padang, from January to Desember 2015. All POAG patients attended were included in the study and collected data included: age, sex, intraocular pressure,cup/disc ratio, and perimetry examination. Result : A total 32 POAG patients of 229 glaucoma patients were included. The number of male patients (81,3\%) more than the female patients (18,7\%). Most common presenting age group was between $51-70$ years old (62.6 \%). Intraocular pressure of 17,2, 3\% patients were above $21 \mathrm{mmHg}$, and 79,7\% patients had below $21 \mathrm{mmHg}$. Most of cup/disc ratio of patients was 0,9-1,0. The perimetry appearance of patients revealed altitudinal defect, arcuate defect, nasal step,temporal island, generalized depression, tunnel vision, and peripheral scotoma.Conclusion : Most of POAG patients were between 51-70 years old, male, and came in advanced clinical appearance.
\end{abstract}

Keywords: POAG, intraocular pressure, cup/disc ratio, perimetry.

Affiliasi penulis : Bagian mata, Fakultas Kedokteran Universitas Andalas

Korespondensi : Fitratul Ilahi fitratul.ilahi@yahoo.com

\section{PENDAHULUAN}

Glaukoma merupakan penyebab utama kebutaan permanen di dunia. Jumlah penderita glaukoma di dunia dari data World Health Organization 60,7 juta orang di tahun 2010, dan diprediksi akan menjadi 79,4 juta di tahun 2020. ${ }^{1}$

Data survey kesehatan mata Departemen Kesehatan Republik Indonesia menunjukkan bahwa glaukoma adalah penyebab kebutaan kedua terbanyak setelah katarak. ${ }^{2}$

TIO merupakan faktor resiko utama dalam berkembangnya glaukoma dan menimbulkan kerusakan papil nervus optikus. Pada penelitian lain disebutkan proporsi pasien dengan POAG yang datang dengan TIO normal pada awal diagnosis cukup tinggi, menunjukkan TIO tidak dapat berdiri sendiri untuk diagnosis glaukoma. Peningkatan usia dan TIO tinggi merupakan faktor resiko konsisten pada beberapa studi prevalensi. Rasio cup/disc dan abnormalitas lapangan pandang saling berhubungan, tetapi terdapat keadaan dimana rasio cup/disc masih dalam batas normal namun sudah terdapat defek lapangan pandang. Namun studi lain juga mengatakan bahwa kehilangan lapangan pandang berkorelasi dengan tampilan papilnya. . $^{3,4}$

Pada penelitian ini akan memperlihatkan gambaran klinis pasien POAG di RSUP Dr. M. Djamil Padang periode Januari - Desember 2015. 


\section{TUJUAN PENELITIAN}

\section{Tujuan Umum}

Mengetahui gambaran umum penderita POAG di RSUP DR M.Djamil Padang

\section{Tujuan Khusus}

1. Untuk mengetahui faktor resiko POAG di RSUP DR M.Djamil Padang periode Januari - Desember 20152.

2. Untuk mengetahui gambaran klinis pasien POAG di RSUP DR M.Djamil Padang

\section{Manfaat Penelitian}

1. Sebagai data dasar untuk penelitian selanjutnya.

2. Sebagai bahan evaluasi dalam penatalaksanaan pasien-pasien POAG di subbagian glaukoma

\section{PRIMARY OPEN ANGLE GLAUCOMA}

Primary Open Angle Glaucoma (POAG) telah menyebabkan kebutaan bilateral pada lebih dari tiga juta orang di dunia dan lebih dari dua juta orang menderita POAG setiap tahunnya. Primary Open Angle Glaucoma (POAG) dikarakteristikkan sebagai neuropati optik yang progresif lambat dengan pola khas kerusakan nervus optikus dan kehilangan lapangan pandang. ${ }^{4,5}$

POAG perjalanan klinisnya progresif lambat dan tanpa nyeri. Pada umumnya bilateral dan dapat asimetris. Karena tajam penglihatan sentral relatif tidak terpapar sampai tahap lanjut dari penyakit, kehilangan lapangan pandang dapat signifikan sebelum gejala lain ditemui. POAG didiagnosa melalui kombinasi dari temuan-temuan, termasuk level tekanan intraokular, tampilan diskus optikus, dan kehilangan lapangan pandang..$^{4,6}$

\section{Faktor Resiko POAG}

\section{Tekanan Intraokular}

Studi epidemiologik berbasis populasi luas menunjukkan bahwa tekanan intraokular rata-rata adalah $15,5 \mathrm{mmHg}$, dengan standar deviasi 2,6 $\mathrm{mmHg}$. Ini menjadikan defenisi tekanan intraokular normal sebagai 2 standar deviasi diatas dan di bawah TIO rata-rata, atau kira-kira $10-21 \mathrm{mmHg}$. Walaupun TIO lebih dari $21 \mathrm{mmHg}$ awalnya didefinisikan sebagai abnormal, definisi ini banyak memiliki kekurangan. Beberapa studi menunjukkan bahwa pada $30-50 \%$ individu dengan neuropati optik glaukomatous dan atau kehilangan lapangan pandang didapat TIOnya adalah dibawah $22 \mathrm{mmHg}^{1,3,4}$

Fluktuasi tekanan intraokular pada pasien glaukoma bervariasi, dari $10 \mathrm{mmHg}$ atau lebih, selama periode 24 jam. Sebagian besar pasien tanpa glaukoma menunjukkan kisaran diurnal $2-6 \mathrm{mmHg}$. Pola diurnal terbagi beberapa tipe tergantung dari waktu tekanan puncaknya : pagi, siang, malam, atau datar (berarti sedikit variasi diurnal). ${ }^{4,6}$

\section{Ras}

Prevalensi POAG 3-4 kali lebih tinggi pada orang kulit hitam daripada kaukasia, selain itu orang kulit hitam enam kali lebih rentan terhadap kerusakan papil nervus optikus daripada kaukasia. Prevalensi rasio cup/disc yang lebih tinggi terdapat pada populasi kulit hitam dibandingkan dengan kulit putih. 4,7

The Barbados Eye Study selama lebih dari 4 tahun menunjukkan 5 kali lebih tinggi insiden glaukoma pada kelompak kulit hitam dengan hipertensi okular dibandingkan dengan populasi kulit putih. Beberapa studi populasi menemukan TIO ratarata pada kulit hitam lebih tinggi daripada kontrol kaukasia. Diperlukan studi lebih lanjut untuk mengklarifikasikan masalah ini. Selain itu, OHTS menyatakan bahwa pasien kulit hitam memiliki CCT (Central Corneal Thickness) rata-rata yang lebih tipis, yang memicu under diagnosis dari tekanan yang meningkat sehingga beresiko lebih tinggi untuk menjadi glaukoma. Karena itu pengukuran pachymetry penting untuk menetapkan baseline untuk pasien Afro Amerika dengan suspek glaukoma. ${ }^{4,7}$

\section{Glaucomatous Optic Nerve dan kehilangan lapangan pandang}

Walaupun peninggian TIO masih dipertimbangkan sebagai faktor resiko utama untuk glaukoma, tetapi tidak lagi menjadi pertimbangan penting untuk diagnosis. Kerusakan papil dan defek lapangan pandang akibat mekanik peningkatan TIO sangat berperanan. Evaluasi periodik papil nervus optikus penting. Kehilangan lapangan pandang harusnya berkorelasi dengan tampilan papilnya. ${ }^{1,7}$

\section{Jenis Kelamin}

Laporan tentang predileksi jenis kelamin berbeda-beda. Beberapa studi telah melaporkan TIO rata-rata lebih tinggi secara signifikan pada wanita daripada pria, sementara studi lainnya tidak menemukan perbedaan, dan terdapat juga yang menemukan bahwa TIO rata-rata lebih tinggi pada pria. $^{2,5}$

Umur

Umur lebih tua dari 40 tahun beresiko untuk mengalami POAG, dengan lebih dari $50 \%$ orang terkena pada dekade ketujuh. Glaukoma lebih sering ditemukan pada populasi tua. Tetapi, POAG sendiri tidak terbatas pada usia pertengahan dan individu yang lebih tua..$^{4,6}$

\section{Kelainan Refraks}

Individu dengan miopia mempunyai kemungkinan meningkatnya resiko untuk menderita glaukoma. penjelasan lain mengenai hubungan antara miopia dengan POAG masih bias, karena seseorang yang mempunyai kelainan refraksi akan memeriksakan matanya sehingga lebih dini terdeteksi daripada orang emetrop. ${ }^{4}$ 


\section{METODE PENELITIAN}

Penelitian dilakukan di instalasi rawat jalan poliklinik mata RSUP Dr. M. Djamil Padang pada bulan Maret 2016.

Penelitian ini bersifat retrospektif deskriptif terhadap pasien POAG di RSUP Dr. M. Djamil Padang dari bulan Januari 2015 - Desember 2015. Data diambil dari rekam medis dan dikelompokkan menurut umur, jenis kelamin, tekanan intraokular, rasio cup/disc, dan hasil perimetri.

Populasi adalah semua pasien yang didiagnosa sebagai POAG. Semua populasi dijadikan sampel.

Kriteria Inklusi

- Pasien yang datang berobat ke subbagian glaukoma poliklinik mata RSUP Dr. M. Djamil Padang dari bulan Januari - Desember 2015.

- Pasien yang sudah didiagnosa oleh subbagian glaukoma sebagai penderita POAG.

- Pasien yang lengkap data catatan rekam medisnya.

Kriteria Eksklusi

- Pasien POAG dengan data yang tidak lengkap

\section{HASIL PENELITIAN}

Selama periode Januari - Desember 2015 terdapat 64 mata (32 kasus POAG) yang kontrol ke poliklinik mata RSUP Dr. M. Djamil Padang.

Tabel 1. Distribusi menurut kelompok usia dan jenis kelamin.

\begin{tabular}{|c|c|c|c|c|}
\hline \multirow[b]{2}{*}{$\begin{array}{l}\text { Kelompok } \\
\text { (tahun) }\end{array}$} & \multirow[b]{2}{*}{ usia } & \multicolumn{2}{|l|}{ Jenis Kelamin } & \multirow[b]{2}{*}{ Total } \\
\hline & & Laki-laki & Perempuan & \\
\hline $31-40$ & & 1 & - & $1(3.1 \%)$ \\
\hline $41-50$ & & 1 & 2 & $3(9,4 \%)$ \\
\hline $51-60$ & & 9 & 1 & $10(31,3 \%)$ \\
\hline $61-70$ & & 7 & 3 & $10(31,3 \%)$ \\
\hline $71-80$ & & 7 & - & $7(21,9 \%)$ \\
\hline $\begin{array}{l}81-90 \\
91-100\end{array}$ & Kelom & umur & terbany & $a k_{3}$, pada \\
\hline
\end{tabular}

Djamil Padang terdapat pada rentang umur 51-60 dan 61-70 tahun (31.3\%) sementara jumlah pasien laki-laki lebih banyak daripada perempuan dengan perbandingan $81,25 \%: 18,75 \%$.

Tabel 2. Distribusi POAG berdasarkan tekanan intraocular

\begin{tabular}{lcc}
\hline \multicolumn{1}{c}{ TIO } & Jumlah (mata) & $\%$ \\
\hline$\leq 21 \mathrm{mmHg}$ & 51 & 79,7 \\
$>21 \mathrm{mmHg}$ & 11 & 17,2 \\
Tidak dapat diukur & 2 & 3,1 \\
\hline Total & 64 & 100 \\
\hline
\end{tabular}

$17,2 \%$ pasien mempunyai tekanan intraokular > $21 \mathrm{mmHg}$, dan $79,7 \%$ di bawah 21 mmHg. 3,1 \% tidak dapat diukur karena ptisis bulbi dan keratopati.

Tabel 3. Distribusi POAG berdasarkan rasio cup/disc dan TIO

\begin{tabular}{lccccc}
\hline Rasio cup/disc & $\begin{array}{c}\text { Jumlah } \\
\text { (mata) }\end{array}$ & $\begin{array}{c}\text { Tidak dapat } \\
\text { diukur }\end{array}$ & $\begin{array}{c}\text { TIO } \\
\mathbf{2 1} \\
\mathbf{m m H g}\end{array}$ & $\begin{array}{c}>\mathbf{2 1} \\
\mathbf{m m H g}\end{array}$ & $\mathbf{\%}$ \\
\hline $0,3-0,8$ & 15 & - & 15 & - & 23,4 \\
$0,8-0,9$ & 12 & - & 8 & 4 & 18,8 \\
$0,9-1,0$ & 23 & - & 4 & 19 & 35,9 \\
$\begin{array}{l}\text { Tidak dapat } \\
\text { dinilai }\end{array}$ & 14 & 2 & 4 & 8 & 18,8 \\
& & & & & \\
\hline Total & $\mathbf{6 4}$ & $\mathbf{2}$ & $\mathbf{3 1}$ & $\mathbf{3 1}$ & $\mathbf{1 0 0}$ \\
\hline
\end{tabular}

Sebagian besar rasio cup/disc adalah 0,9-1,0 yaitu 23 mata (35,9\%). 4 di antaranya dengan TIO $\leq$ $21 \mathrm{mmHg}$, dan 19 mata TIOnya adalah $>21 \mathrm{mmHg}$. $18,8 \%$ tidak dapat dinilai karena media keruh (katarak).

Kesan perimetri dari pasien-pasien POAG yang didapatkan adalah : skotoma arkuata, nasal step, temporal island, defek altitudinal, tunnel vision, generalized depression, dan skotoma perifer.

\section{DISKUSI}

Selama periode Januari - Desember 2015 terdapat 32 kasus POAG (64 mata) yang kontrol ke poliklinik mata RSUP Dr. M. Djamil Padang. Kelompok umur terbanyak pada pasien POAG yang kontrol ke poliklinik mata RSUP Dr. M. Djamil Padang terdapat pada rentang umur 51-60 dan 61-70 tahun (31.3\%), sementara jumlah pasien laki-laki lebih banyak daripada perempuan dengan perbandingan $81,3 \%$ : $18,7 \%$. Vitresia $\mathrm{H}$ dalam penelitiannya mendapatkan terdapat peningkatan prevalensi POAG dengan usia yaitu dari 0,62 \% pada kelompok umur 40-49 tahun menjadi 1,1 \% pada kelompok umur di atas $70 \mathrm{di}$ Sumatra Barat, Indonesia. Berdasarkan umur, juga didapatkan lebih banyak pada laki-laki dibanding wanita. $^{2,7}$

Sebagian besar pasien mempunyai tekanan intraokular di bawah $21 \mathrm{mmHg}(79,7 \%)$ yaitu pasien yang sudah kontrol berulang kali dan mendapatkan pengobatan anti glaukoma, sehingga kemungkinan TIO sudah terkontrol dengan obat. Akan tetapi beberapa studi menunjukkan bahwa pada $30-50 \%$ individu dengan neuropati optik glaukomatous dan atau kehilangan lapangan pandang skrining awalnya TIOnya adalah dibawah $22 \mathrm{mmHg} .4,8,9$,

Sebagian besar rasio cup/disc adalah 0,9-1,0 yaitu 35,9 \%, 4 diantaranya dengan $\mathrm{TIO} \leq 21 \mathrm{mmHg}$, dan 19 mata TIOnya adalah $>21 \mathrm{mmHg}$. Quigley $\mathrm{AH}$ et al menemukan pasien dengan POAG memiliki rasio cup/discnya $0,71 \pm 0,23$ pada 178 mata yang ditelitinya di Arizona. $^{6}$ Secara umum walaupun keadaan rasio cup/disc yang didapatkan sudah lanjut namun sebagian besar TIO nya $\leq 21 \mathrm{mmHg}$, kemungkinan telah terkontrol dengan obat. Namun pada rasio cup/disc 0,9-1,0 sebagian besar pasien TIOnya $>21 \mathrm{mmHg}$, beberapa di antaranya dengan diagnosa glaukoma absolut dan terdapat juga kasus dimana TIOnya belum terkontrol. Ini menunjukkan bahwa sebagian besar pasien datang dengan tampilan POAG yang sudah lanjut, menandakan perlu adanya deteksi awal akan mulai timbulnya POAG. Ou Y menyebutkan bahwa jumlah pasien dengan TIO $>21$ $\mathrm{mmHg}$ yang memiliki glaucomatous optic neuropathy adalah bervariasi, dari 13 persen studi di italia utara sampai 71 persen di Barbados. The Advanced 
Glaucoma Intervention Study (AGIS) dalam studi selama 6 tahun menyatakan bahwa pasien dengan TIO di bawah $18 \mathrm{mmHg}$ terlihat lebih stabil perjalanan penyakitnya dibandingkan dengan yang $\mathrm{TIO}>18$ $\mathrm{mmHg} .{ }^{10}$ Kesan perimetri dari pasien-pasien POAG adalah bervariasi, yaitu : skotoma arkuata, nasal step, temporal island, defek altitudinal, tunnel vision, generalized depression, dan skotoma perifer.

Pasien POAG biasanya ditemukan secara kebetulan pada pasien yang datang dengan keluhan penyakit mata selain glaukoma, karena tidak adanya gejala awal. Oleh karena itu banyak kasus yang tidak terdeteksi awal dan datang dengan tampilan klinis yang lanjut. Hal ini mengindikasikan perlunya program intervensi untuk deteksi dan rujuk dini kasus-kasus POAG untuk mencegah kehilangan visus yang signifikan.

\section{KESIMPULAN}

1. Selama periode Januari - Desember 2015 terdapat 32 kasus POAG (64 mata) yang kontrol ke poliklinik mata RSUP Dr. M. Djamil Padang dengan Kelompok umur terbanyak adalah 51-70 tahun dan jumlah pasien laki-laki lebih banyak daripada perempuan.

2. Banyaknya pasien dengan TIO terkontrol (< $21 \mathrm{mmHg}$ ) dikarenakan pasien sudah mendapatkan obat anti glaukoma, namun sebagian besar pasien datang dengan tampilan POAG yang sudah lanjut.

\section{SARAN}

Karena sebagian besar kasus POAG datang dengan tampilan klinis yang lanjut maka perlu adanya program untuk deteksi dan rujuk dini kasuskasus POAG untuk mencegah kehilangan visus yang signifikan.

\section{DAFTAR PUSTAKA}

1. Shaarawy TM,Sherwood MB,Crowston J Glaucoma Medical Diagnosis and Therapy, Volume One. UK: Saunders Elsivier, 2009. P. 114

2. Vitresia H, Profil Glaukoma di Propinsi Sumatera Barat, Indonesia. Padang: Bagian Mata, Universitas Andalas, RS Dr.M.Djamil. 2008. P.37-43

3. Foster PJ,Buhrmann,Quigley. The Definition and Classification of Glaucoms in Prevalence Surveys. Br J Ophthalmol,2002. P. 238-242

4. Skuta GL, Cantor LB, Weiss JS. Open Angle Glaucoma. In: Glaucoma, Section 10. San Francisco: American Academy of Ophthalmology. 2012. P. 191-207.

5. Rashid W, Rather S, Singh T. Profile of Patients of Glaucoms in Kashmir Valley (A Hospital Based Study). JK Science. Vol 12 No.3, 2010. P. 137139

6. Quigley,SK west,Rodrigues J. The Prevalence of Glaucoma in a Population -Based Study of Hispanic Subject: Proyecto VER. Arc Ophthalmol, Vol 119, 2001. P. 1819-1826

7. Krishnadas R, Puthuran GV. Prevalence of Glaucoma in India and The World. Tamil Nadu Journal of Opthalmology $\mathrm{Vol} 47$, Issue 4
8. Foster PJ,Buhrmann,Quigley. The Definition and Classification of Glaucoma in Prevalence Surveys. Br J Ophthalmol, 2002. P. 238-242

9. Rahman MM,,Rahman N,Haque Z,Zaman AU,Dineen B. The Prevalence of Glaucoma in Bangladesh: a population based survey in Dhaka Divison. Br J Ophthalmol, 2004.P. 1493-1497

10. Ou Y. The role of IOP. In: Managing Glaucoma and Intraocular Pressure. Review of Opthalmology. 2014 